\title{
VHF radar observations of turbulent structures in the polar mesopause region
}

\author{
P. Czechowsky and R. Rüster \\ Max-Planck-Institut für Aeronomie, Postfach 20, 37189 Katlenburg-Lindau, Germany
}

Received: 27 November 1996 / Revised: 20 February 1997 / Accepted: 24 February 1997

\begin{abstract}
The mobile SOUSY VHF Radar was operated in the summer of 1987 during the MAC/SINE campaign in northern Norway to study the polar mesosphere summer echoes (PMSE). Measurements of the spectral width indicate that two types of structures occur. In general mesospheric layers are bifurcated exhibiting a narrow spectral width and a well-defined aspect sensitivity. However, for about $10 \%$ of the observation time cells of enhanced turbulence characterized by extremely broad spectral widths appear predominantly in the upper sublayer above $86 \mathrm{~km}$. Identification and separation of beam and shear broadening allows a determination of the turbulence-induced component of the spectral width. This case study reveals that during several events these cloud-like structures of enhanced turbulence move with an apparent velocity of several tens of meters per second which is almost identical with the phase trace velocity of simultaneously observed waves. Since, at that time, the Richardson number was less than a quarter, it was concluded that these turbulent cells were generated by a Kelvin-Helmholtz mechanism. The horizontal extent of these structures was calculated to be less than $40 \mathrm{~km}$. A general relation between spectral width and echo power was not detected. The turbulent component of the spectral width was used to calculate typical values of the energy dissipation rate at times where narrow spectral width dominates and during periods of enhanced turbulence. In addition, the outer scale of the inertial subrange (buoyancy scale) was estimated. For the first time the occurrence and motion of this type of structures of enhanced spectral width is analyzed and discussed in detail.
\end{abstract}

\section{Introduction}

Radar measurements at Andenes, Norway $\left(69^{\circ} \mathrm{N}, 16^{\circ} \mathrm{E}\right)$ were performed with the mobile SOUSY system to study the nature of echo structures, wave dynamics and

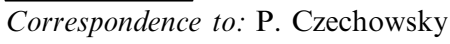

turbulence in the summer mesosphere. Scattering was detected from layers at heights between about 80 to $92 \mathrm{~km}$, which are quite often split into two sublayers, one above and one below $86 \mathrm{~km}$. In some cases these structures descend with an apparent velocity of about $1 \mathrm{~km} \mathrm{~h}^{-1}$ (see e.g., Ecklund and Balsley, 1981; Rüster, 1984; Czechowsky et al., 1989; Cho and Kelly, 1993). In general these polar mesospheric summer echoes (PMSE) are dominated by narrow spectral widths and strong aspect sensitivities (Czechowsky et al., 1988). In the upper sublayer, however, cells of intense turbulence appear sporadically, expressed by sudden increases of the spectral width by a factor of up to four. Power bursts which were observed in connection with KelvinHelmholtz instabilities (KH1) as reported by Klostermeyer and Rüster (1984) and by Rüster and Klostermeyer (1987) were detected only twice in connection with these cells.

The objective of this investigation is to discuss the occurrence, the motion and the horizontal extent of these cells of enhanced spectral width as well as their generation mechanism and to present an estimation of the energy dissipation rate.

\section{Experiment}

Since the design of the mobile SOUSY radar and the various components have already been described in detail (Schmidt et al., 1979; Czechowsky et al., 1984), only the relevant technical parameters of the system located at Andenes/Norway will be presented here. During all campaigns the radar was operated in the Doppler-beam-swinging mode. The radar transmits at a frequency of $53.5 \mathrm{MHz}$, with a peak pulse power of $150 \mathrm{~kW}$ and a duty cycle of $4 \%$. A 16-bit complementary code was applied to use the maximum duty cycle without deteriorating the range resolution. Each code element being $2 \mu \mathrm{s}$ long corresponds to a range resolution of $300 \mathrm{~m}$. The antenna system is a phased array consisting of 576 Yagi elements with a gain of $35.5 \mathrm{~dB}$. The main beam can be steered electronically in six directions towards the NE, NW, and SW at an off- 
zenith angle $\mathrm{ZD}=4^{\circ}$, towards $\mathrm{N}$ and $\mathrm{W}$ at $\mathrm{ZD}=5.6^{\circ}$ and vertically. The radiation pattern has a one-way half power width of $3^{\circ}$ and at a height of $86 \mathrm{~km}$ illuminates six areas with diameters of $4.5 \mathrm{~km}$, each of them separated by $6 \mathrm{~km}$. The observations have been carried out continuously from June 15 to July 19, 1987.

\section{Results}

\subsection{Beam and shear broadening}

Figure 1 presents a characteristic example of the echo intensity measured from 0828 to 1046 LT on July 14, 1987 in all six beam directions. During a very active period of about $3 \mathrm{~h}$, starting at $0905 \mathrm{LT}$, the signal-tonoise ratio $(\mathrm{S} / \mathrm{N})$ exceeds $36 \mathrm{~dB}$ indicated by the dark red color. Around $0950 \mathrm{LT}$ the onset of an oscillation with a period of about $18 \mathrm{~min}$ is observed in all beam directions in the lower part of the layer. The phase shows a clear progression from west (lower panel) towards northeast (upper panel) within $10 \mathrm{~min}$. This phase shift is comparable to the eastward drift of cells of enhanced spectral width $\left(\sigma_{\text {total }}\right)$ shown in Fig. 2 . This height-time intensity plot presents $\sigma_{\text {total }}$ observed in the six different beam positions (NE on top to $\mathrm{W}$ on bottom). The total spectral widths have been calculated directly from the second moment of the signal power spectrum. These values contain contributions due to wind shear $\left(\sigma_{\text {shear }}\right)$, beam broadening $\left(\sigma_{\text {beam }}\right)$ and turbulence $\left(\sigma_{\text {turb }}\right)$ :

$\sigma_{\text {total }}^{2}=\sigma_{\text {turb }}^{2}+\sigma_{\text {beam }}^{2}+\sigma_{\text {shear }}^{2}$

The term $\sigma_{\text {turb }}^{2}$ represents the mean square fluctuating velocity within the illuminated volume. The dark red shaded area corresponds to $7.53 \mathrm{~m} \mathrm{~s}^{-1}$, which is equal to the second moment of a finite white-noise-spectrum.

During the entire time interval of more than $2 \mathrm{~h}$, presented in Fig. 2, narrow spectral widths dominate (dark blue color). In the upper part of the layer cells of enhanced spectral width (yellow and red color) occur suddenly, partly without any transition between one height bin and the following. These structures were observed first at about 0920 LT as the antenna beam was directed towards the west and lastly in the northeast beam and seem to move in an eastward direction. In general the lifetimes of the cells of enhanced spectral width vary between 5 and $30 \mathrm{~min}$, as concluded from an investigation of about 20 such events, which were detected in less than $10 \%$ of the total observation time given in Sect. 2.

In order to investigate the nature of these structures in detail, the turbulent contribution $\sigma_{\text {turb }}$ of $\sigma_{\text {total }}$ has to be separated by eliminating the beam and shear broadening. Beam broadening depends on the half power width $\theta$ of the main beam of the antenna radiation pattern and on the horizontal wind speed $V$ (Gossard, 1990):

$\sigma_{\text {beam }}^{2}=V^{2}(\theta / 2)^{2} / 2.76$.

At near-vertical beam pointing angles, shear broadening is determined from $\beta_{r}$, the radial gradient of the radial component of the wind (Gossard, 1990): $\sigma_{\text {shear }}^{2}=\left(\beta_{r} \Delta r\right)^{2} / 12$

with

$\beta_{r}=(\Delta V / \Delta z) \sin (Z D)$,

where $\Delta r$ and $\Delta z$ are the resolutions in the oblique and vertical directions, respectively.

This formula can be applied, if the main lobe of the antenna radiation pattern has an almost pencil beam characteristic as e.g., the antenna of the SOUSY radar with a half power width of $3^{\circ}$. The largest vertical gradient $\Delta V / \Delta z$ was observed on July 14 from 0926 to 0945 LT as illustrated in Fig. 3. This diagram presents the averaged wind vector in the height range from 83 to $91 \mathrm{~km}$ yielding a maximum shear of $80.6 \mathrm{~m} \mathrm{~s}^{-1} \mathrm{~km}^{-1}$ above $88.5 \mathrm{~km}$ corresponding to a broadening of $\sigma_{\text {shear }}=0.46 \mathrm{~m} \mathrm{~s}^{-1}$.

Profiles of all three components $\left(\sigma_{\text {turb }}, \sigma_{\text {beam }}\right.$ and $\left.\sigma_{\text {shear }}\right)$ at times of broadest spectral width from 0926 to 0945 LT are shown in Fig. 4 demonstrating that $\sigma_{\text {shear }}$ (plusses) is small compared to the turbulent component $\sigma_{\text {turb }}$ (circles). Furthermore, indications for strong shear broadening as, e.g., an increase of the spectral width with zenith distance was not detected. In general shear broadening can be ignored if the radar pulse length is short (less than or equal to $2 \mu \mathrm{s}$ ) and if the antenna beam is narrow (less than or equal to $5^{\circ}$ half power width) and directed vertically.

The scatter plot (Fig. 5) presents the relation between the total spectral width $\sigma_{\text {total }}$ and the wind speed at periods of low $\left(\sigma_{\text {total }}<3 \mathrm{~m} \mathrm{~s}^{-1}\right.$, upper panel) and enhanced $\left(\sigma_{\text {total }} \geq 3 \mathrm{~m} \mathrm{~s}^{-1}\right.$, lower panel $)$ turbulence. Each circle $(z \geq 86 \mathrm{~km})$ and asterisk $(z<86 \mathrm{~km})$ denotes a single data point for a specific height bin and time interval with a resolution of $300 \mathrm{~m}$ and $1 \mathrm{~min}$, respectively, within the altitude range from 82 to $91 \mathrm{~km}(\mathrm{~S} / \mathrm{N}>-6 \mathrm{~dB})$. The solid and the dashed lines represent $\sigma_{\text {beam }}$ for one-way and two-way beam broadening, respectively. This diagram clearly illustrates the increase of the total spectral width with the wind speed caused by beam broadening and indicates in addition that this contribution is less than $1.6 \mathrm{~m} \mathrm{~s}^{-1}$ for wind speeds up to $100 \mathrm{~m} \mathrm{~s}^{-1}$, since the half power beam width is only $3^{\circ}$. The spectral width during non-turbulent time periods from 0844 to $0908 \mathrm{LT}$ (upper panel) is generally smaller than $3 \mathrm{~m} \mathrm{~s}^{-1}$. Spectral widths narrower than the calculated one-way beam broadening may be caused by Fresnel scattering and/or Fresnel reflection. In this case the received echo power and in turn the spectral width depend on the square of the effective antenna area (Röttger and Larsen, 1990), which can be transferred to the two-way beam width (dashed line). The respective results for the period of enhanced turbulence (lower panel), however, indicate two distinct areas. Narrow spectral width, comparable to the picture in the upper diagram, is primarily detected in the lower part of the layer (asterisks), whereas $\sigma$-values from the upper sublayer above $86 \mathrm{~km}$ range from about 3.0 to $7.5 \mathrm{~m} \mathrm{~s}^{-1}$ (circles). If shear and beam broadening are subtracted, the remaining component of the spectral width is predominantly due to turbulence, in particular 


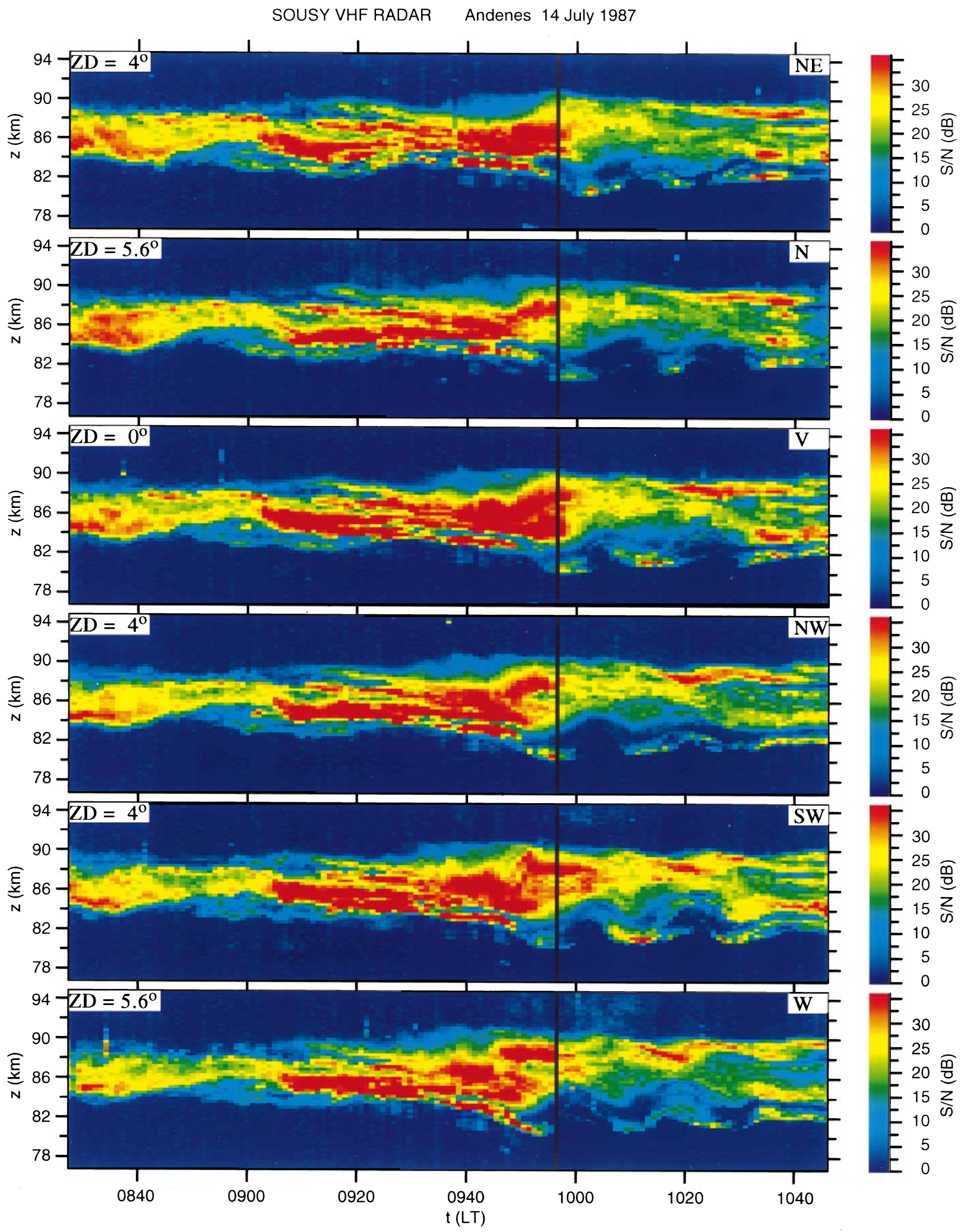

Fig. 1. Height-time plots of the echo intensity observed in six different beam directions on 14 July 1987

if the beam is tilted and the partially reflected contribution is decreasing. A further criterion, that these structures of enhanced spectral width are for the most part related to turbulence is supported by the absence of aspect sensitivity which was derived for the same time and height intervals. 
SOUSY VHF RADAR Andenes 14 July 1987

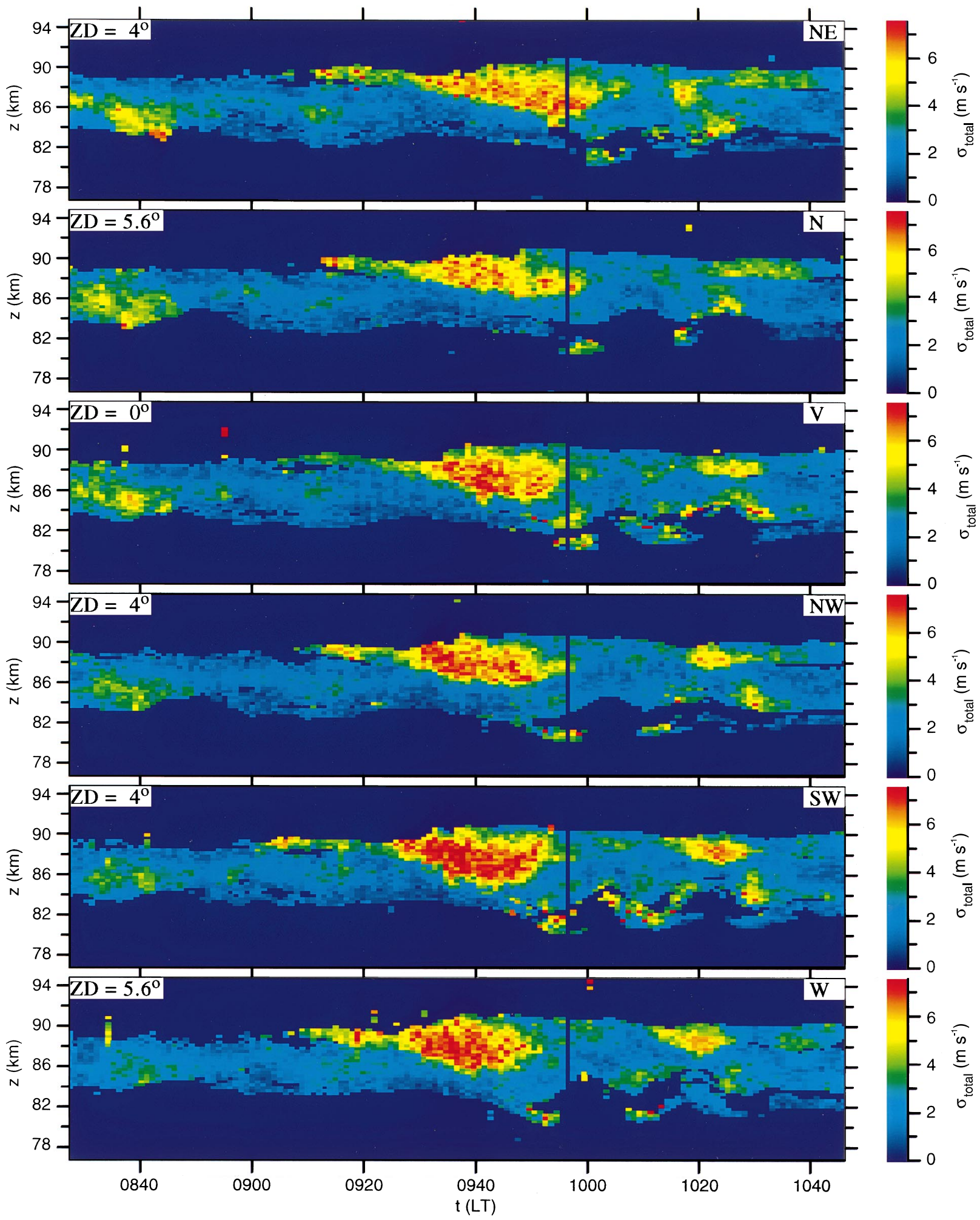

Fig. 2. Height-time plots of the total spectral width observed in six different beam directions

\subsection{Relation between spectral width and echo power}

Observations carried out continuously in the summer 1987 (see Sect. 2) clearly indicate that PMSE can be classified into two categories. The general dominating type exhibits narrow spectral width and a well-defined aspect sensitivity (Czechowsky et al., 1988), which is detected for 80 to $90 \%$ of the time within all observed layers. In the upper sublayer well-defined cells of broad spectral widths are observed sporadically. The transition 
SOUSY VHF RADAR ANDENES 14 July 1987 Horizontal velocity

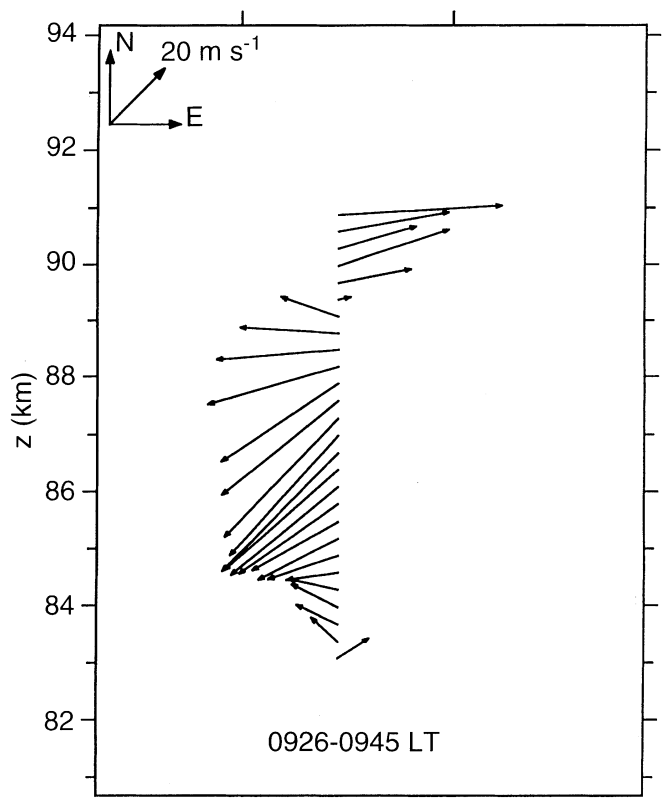

Fig. 3. Wind profile during a period of enhanced spectral width

from small to large values occurs within less than a minute as illustrated in Fig. 2. For long time averages the spectral width increases with height.

At mid-latitudes Thomas et al. (1992) have investigated PMSE-like structures occurring predominantly in a single layer with a height extension of 3 to $5 \mathrm{~km}$ centered around $85 \mathrm{~km}$. The detected cells of enhanced spectral width cover the whole layer contrary to the

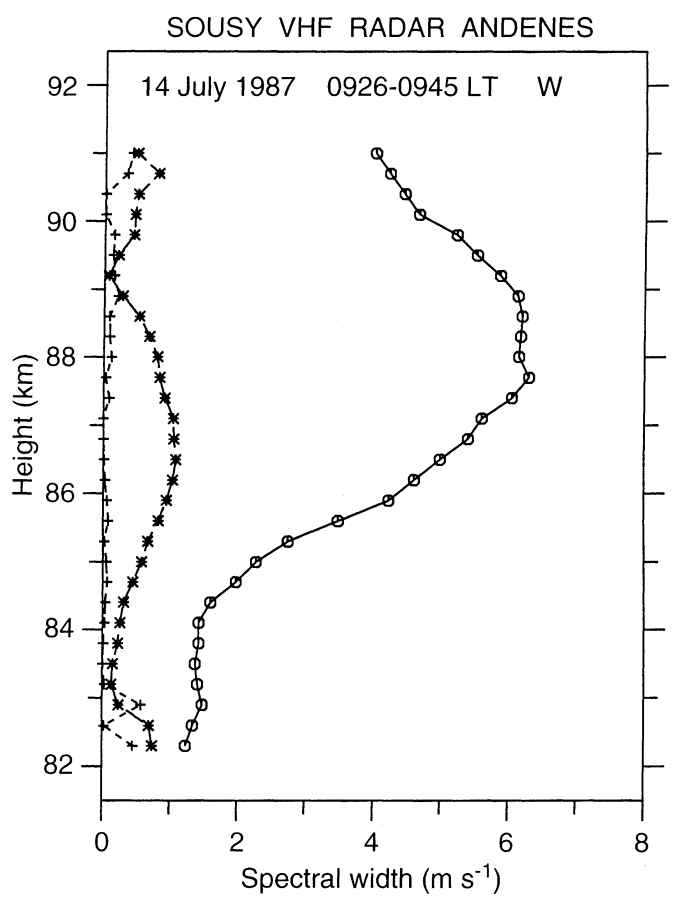

Fig. 4. Height profiles of beam (asterisks) and shear (plusses) broadening and of the turbulent component of the spectral width (circles)

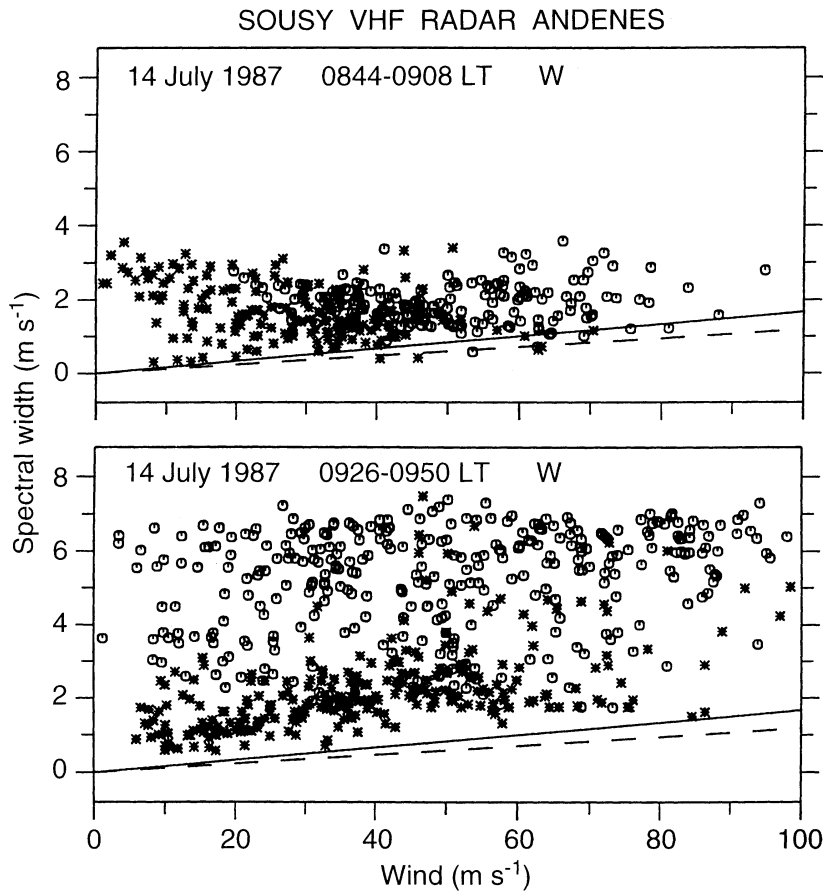

Fig. 5. Scatter plots of total spectral width and wind speed at heights above (circles) and below (asterisks) $86 \mathrm{~km}$ for weak (upper panel) and strong (lower panel) turbulence. The solid and the dashed lines indicate the limits of one- and two-way beam broadening, respectively

distribution at polar latitudes (Fig. 2). Echoes with broad spectral width show the tendency to increase with increasing $\mathrm{S} / \mathrm{N}$. Echoes with narrow spectral width seem to be independent of the received power, partly with a slight negative slope.

Figure 6a shows characteristic examples of spectral width as a function of $\mathrm{S} / \mathrm{N}$ observed at polar latitudes. As in Fig. 5 each symbol denotes an unaveraged data point with a height and time resolution of $300 \mathrm{~m}$ and $1 \mathrm{~min}$, respectively. To reduce the contribution from partial reflections, signals received from westward directed beams were mainly used in this analysis. During the four events on June 22, 26, 27 and on July 14, cells of enhanced spectral width, similar to the structures shown in Fig. 2, were observed. The circles and the asterisks represent values derived from heights above and below the center of the layer $(z=86 \mathrm{~km})$, respectively. As demonstrated in these scatter plots, narrow spectral width $\left(\sigma_{\text {turb }}<2.5 \mathrm{~m} \mathrm{~s}^{-1}\right)$ is to some extent increasing (panels on the right) or decreasing (upper left panel) with the $\mathrm{S} / \mathrm{N}$ and is, therefore, only slightly correlated with $\mathrm{S} / \mathrm{N}$. In most cases, however, uncorrelated distributions dominate (lower left panel) and represent the long time average.

Klostermeyer (1997) has derived a relation between the radar reflectivity $\eta$ and the variance of the vertical velocity $w^{\prime}$ which is related to the turbulent component of the spectral width $\left(\sigma_{t u r b}\right)$. He found, that large $w^{\prime}$ are positively correlated with $\eta$ which is in agreement with measurements carried out at mid-latitudes (Thomas et al., 1992; Thomas and Austin, 1994). In summer 1987, however, only two examples were observed at 


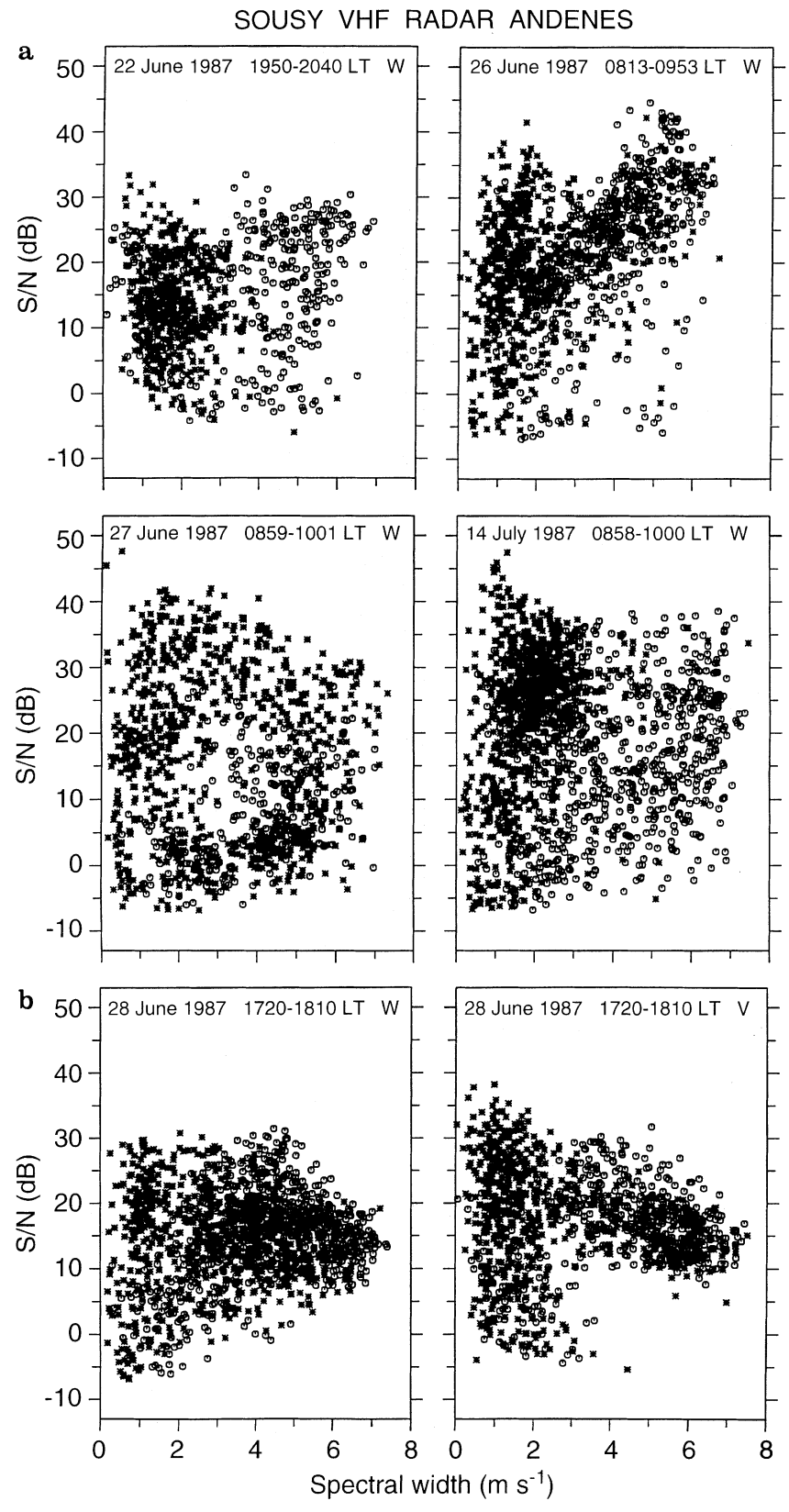

Fig. 6a. Scatter plots of $\sigma_{\text {turb }}$ and $\mathrm{S} / \mathrm{N}$ observed in the upper (circles) and lower (asterisks) sublayer of PMSE. b Scatter plots of $\sigma_{\text {turb }}$ and $\mathrm{S} / \mathrm{N}$ observed for antenna beams directed towards west (left panel) and vertically (right panel)

polar latitudes exhibiting a similar tendency as illustrated in the upper right panel of Fig. 6a. For this event a positive correlation coefficient of 0.43 was calculated based on 519 data points all exceeding a spectral width $\sigma_{\text {turb }}$ of $2.5 \mathrm{~m} \mathrm{~s}^{-1}$ leading to a Fisher test value of 117.3 . The resulting error probability of the correlation coefficient is, therefore, less than $0.1 \%$ (e.g., Taubenheim, 1969). The small correlation coefficient is caused by outliers as e.g., for spectral widths greater than $4 \mathrm{~m} \mathrm{~s}^{-1}$ and signal-to-noise ratios less than $10 \mathrm{~dB}$. Decreasing $\mathrm{S} / \mathrm{N}$ with increasing spectral width or turbulence intensity demonstrated in the right panel of Fig. 6b, were observed only once in the vertically pointing beam on
June 28, 1987. The statistical analysis of these 586 data points yields a correlation coefficient of -0.38 , a Fisher test value of 98.6 and an error probability of less than $0.1 \%$. This decrease of the echo power with increasing spectral width (Fig. 6b, right panel) is probably caused by the influence of partial reflection. Observations with a westward pointing beam, however, exhibit no such correlation (Fig. 6b, left panel).

\subsection{Motion and horizontal extent of cells of enhanced spectral width}

As mentioned in Sect. 3.1 the turbulent structures illustrated in Fig. 2 move with an apparent velocity of some tens of meters per second. Figure 7 shows time series of the height integrated turbulent component of the spectral width. The first increase of the spectral width was observed at about 0926 LT in the westward pointing beam. The total event lasted for about $25 \mathrm{~min}$ and progressed from west towards northeast within 10 min. From these six time series of $\sigma_{\text {turb }} 15$ pairs were formed for calculating cross-correlation functions. Their maxima were used to derive the accurate time difference between the occurrence of these bursts at all beam directions. Since the spacing of the illuminated volumes at heights between 86 and $88 \mathrm{~km}$ is defined by the antenna tilt angle, the relevant components of the phase trace velocity (towards N, NE, E, SE) could be calculated, and in turn the resulting speed and direction. The main turbulent cell moves with an apparent velocity $c_{c}=22 \mathrm{~m} \mathrm{~s}^{-1}$ approximately towards the east. Smaller structures of enhanced spectral width were detected starting at $1010 \mathrm{LT}$ when the antenna beam was directed towards W, SW, NW and vertical and at $1020 \mathrm{LT}$ in the NE direction. The spectral analysis of these time series leads to two dominating periods of $46.3 \mathrm{~min}$ and 18.3 min. A similar event observed on July 28, 1987, showed the same main features, as the onset occurring first in the westward direction. The phase trace speed in

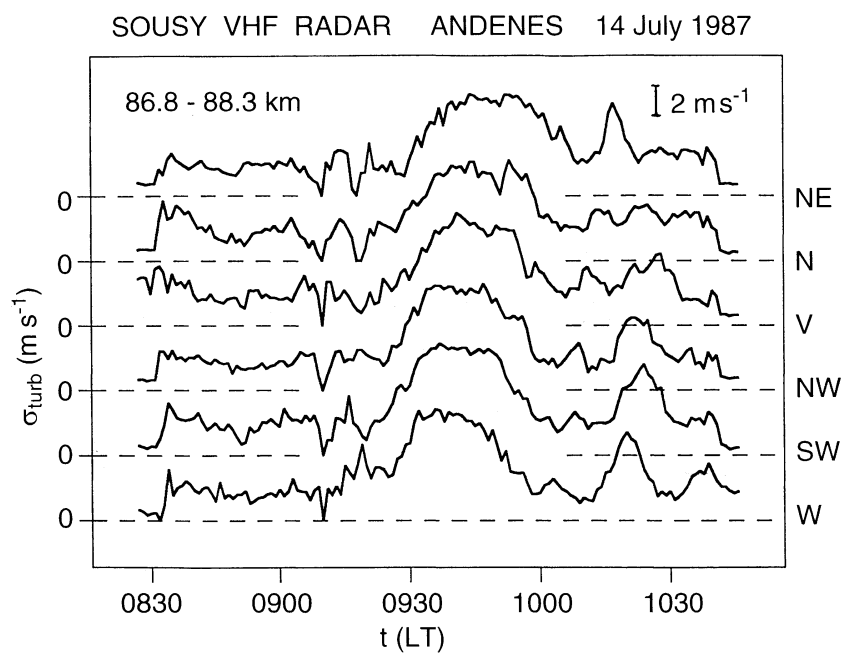

Fig. 7. Height integrated $(86.2-88.3 \mathrm{~km})$ time series of the turbulent component $\sigma_{\text {turb }}$ of the spectral width observed in all six beams 
this case was calculated to be about $26 \mathrm{~m} \mathrm{~s}^{-1}$. The apparent velocities and the time intervals of occurrence allowed an estimation of the horizontal extent of these structures, resulting in $37 \mathrm{~km}$ (June 14) and $32 \mathrm{~km}$ (July 28), respectively. During several campaigns carried out in Andenes and Kiruna, radar and rocket measurements were compared to study the fine structure of PMSE (see e.g., Inhester et al., 1990; Hoppe et al., 1994). Some discrepancies between ground based and in situ measurements in particular in the upper sublayer may result from the spacings between the radar illuminated volumes and the trajectories of the rockets, which were frequently larger than the horizontal extent of these specific mesospheric structures as demonstrated already.

\section{Discussion}

\subsection{Generation of cells of enhanced spectral width}

As shown in Figs. 1 and 2, the occurrence of cells of enhanced spectral width is connected with the onset of a wavelike variation of the echo power. Figure 8 shows the temporal variation of the radial velocities measured with a westward tilted beam. The stippled area representing the height and time interval of enhanced turbulence, coincides with the onset of a wave with a period of about 18 to $19 \mathrm{~min}$, which appears within the entire height range of that layer from about 82 to $91 \mathrm{~km}$. The wave amplitude maximizes at heights from 84.7 to $86.2 \mathrm{~km}$ (slightly below the center of the enhanced spectral width) and this interval, therefore, was chosen for the spectral analysis. Figure 9 presents height integrated low-pass filtered time series (five point running mean with binominal weighting) of the radial velocities observed at all six beams. The harmonic analysis yields a mean period for all six time series of about $19 \mathrm{~min}$ which is comparable to that of the periodic fluctuations of $\sigma_{\text {turb }}$ (Fig. 7) and to that of the height variations of the layer (Fig. 2).

The phase shift of the 19-min oscillation (Fig. 9) from west to northeast is very similar to that of the $\sigma_{\text {turb }}$ structures (Fig. 7). Applying the same correlation

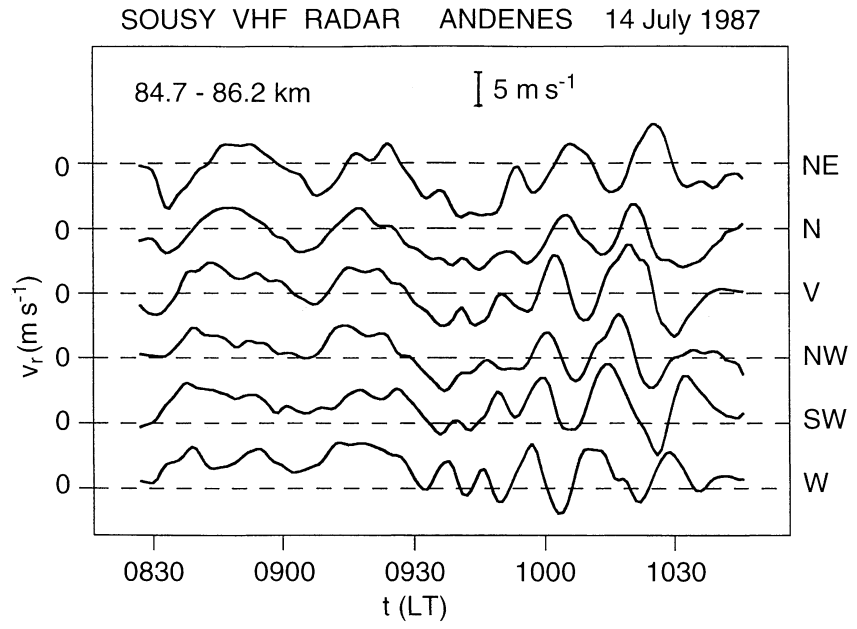

Fig. 9. Height integrated $(84.3-86.2 \mathrm{~km})$ time series of the radial velocities observed in all six beams

analysis as mentioned already (with 15 cross-correlations) yields the respective phase trace velocity of the wave $c_{w}=19 \mathrm{~m} \mathrm{~s}^{-1}$. This value agrees quite well with $c_{c}$, derived for $\sigma_{t u r b}$ structures, as shown in the vector diagram of Fig. 10. The averaged height profile of the background wind clearly reveals a strong shear with a significant directional change in the height range from about 88.4 to $91 \mathrm{~km}$ (Fig. 3), resulting in a minimum Richardson number of $R_{i}=0.15$, if a zero temperature gradient at mesopause heights is assumed (von Zahn and Meyer, 1989; Lübken and von Zahn, 1991). It may be argued, therefore, that turbulent structures and the simultaneously observed waves were generated by a KHI mechanism since the Richardson number is less than a quarter.

\subsection{Energy dissipation rates}

If the mean square fluctuating vertical velocity $\sigma_{t u r b-v}$ is entirely caused by turbulence (beam and shear broadening were subtracted as well as spectral spikes due to quasi specular reflections, Hocking, 1983) and if the

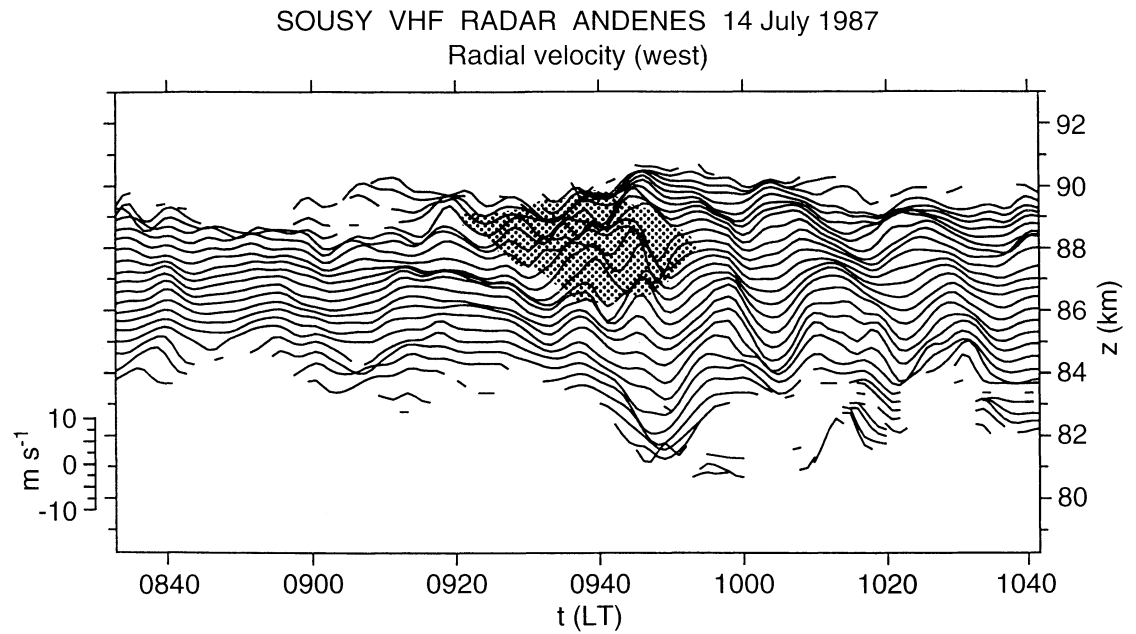

Fig. 8. Radial velocities versus time observed with a westward pointing beam. The stippled area denotes the extent of the structure of enhanced turbulence 


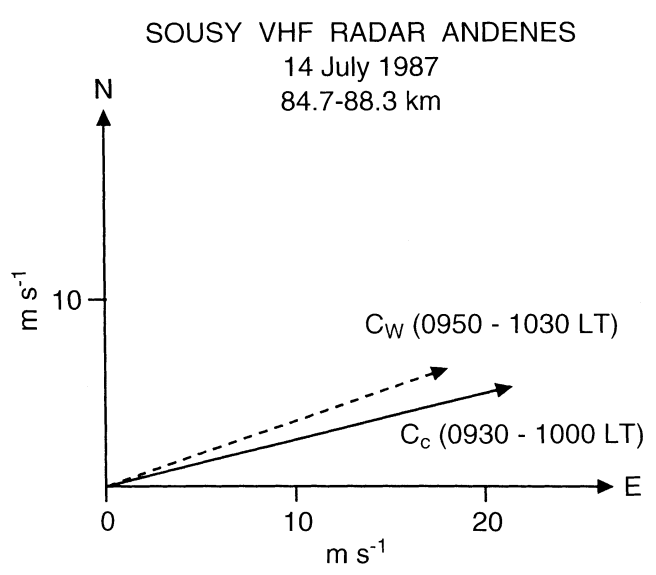

Fig. 10. Vector diagram of the phase trace velocities of the observed wave $c_{w}$, and the turbulent cells $c_{c}$

Brunt-Väisälä frequency $\omega_{B}>0$, the energy dissipation rate $\epsilon$, can be derived (Weinstock, 1981)

$\epsilon=0.45 \sigma_{\text {turb-v }}^{2} \omega_{B}$

for radar wavelengths being small compared to $L_{B}$, the outer scale of the inertial subrange (buoyancy scale). In addition $\epsilon$ can be used to calculate $L_{B}$ (Weinstock, 1981):

$L_{B}=6.9 \sigma_{t u r b-v} / \omega_{B}$.

Based on the mean background temperature measured in Andenes in June and July 1987 by von Zahn and Meyer (1989), $\omega_{B}$ and in turn $\epsilon$ and $L_{B}$ were calculated during weak (0850-0907 LT) and intense (0935-0952 LT) turbulence from $\sigma_{\text {turb-v }}$.

It should be noted, that in this study $\epsilon$ is derived from the spectral width and not from the signal-to-noise ratio. PMSE can cause spikes superimposed on the broad turbulent spectrum, which were removed prior to the analysis (according to Hocking, 1983).

The energy dissipation rate is a parameter related to the neutral gas. The radar, however, measures variations of the refractive index due to variations of the electron density with scales equal to half the radar wavelength (Bragg-condition). Broad spectra of the received radar signals are caused by fast phase variations of the Fourier component of the electron density corresponding to the radar wavelength. At a height below $95 \mathrm{~km}$ the electron density is coupled by electromagnetic forces to fluctuations of the ion density (or charged dust, or ice particles) and in turn by collisions to the variation of the neutral gas. Above about $95 \mathrm{~km}$, however, a decoupling between density fluctuations of electrons and ions and in turn of neutral particles can be caused by strong electric fields.

The asterisks in Fig. 11 represent a characteristic height profile of $\epsilon$ ranging from $20 \mathrm{~mW} \mathrm{~kg}^{-1}$ in the lower part of the layer up to values of $80 \mathrm{~mW} \mathrm{~kg}^{-1}$ at heights of $89 \mathrm{~km}$. This behavior is observed in 80 to $90 \%$ of the time in summer. It is comparable with measurements carried out during PMSE with the Poker Flat Radar in Alaska (Watkins et al., 1988).

Extremely large values of $\epsilon$ of up to $500 \mathrm{~mW} \mathrm{~kg}^{-1}$ as indicated by the circles, are observed only for about

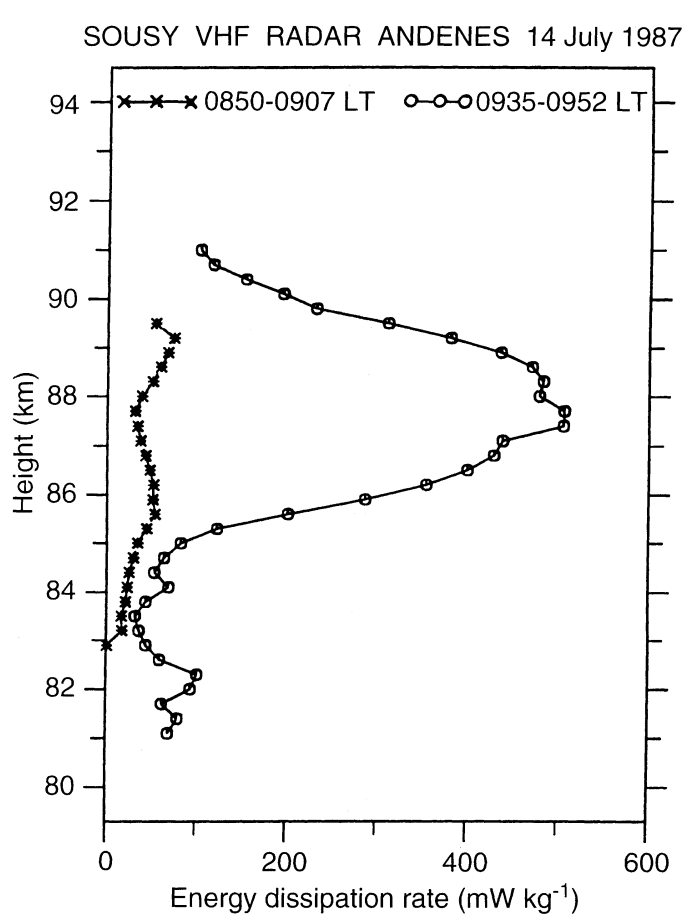

Fig. 11. Height profiles of energy dissipation rates at time periods of broad (circles) and narrow (asterisks) spectral width

$10 \%$ of the time during periods of enhanced turbulence. It should be noted again, that no aspect sensitivity was detected within the same height and time interval, which is a strong hint for an isotropic scattering process and in turn for turbulence. Watkins et al. (1988) reported that similar values of $\epsilon$, exceeding $1 \mathrm{~W} \mathrm{~kg}^{-1}$, were observed above $86 \mathrm{~km}$ over Alaska lasting for only a few minutes.

The energy dissipation rate derived from in situ measurements carried out during several rocket campaigns in northern Norway (DYANA, NLC-91, METAL, SCALE: Lübken, 1992; Lübken et al., 1993; Lübken et al., 1994) shows a similar tendency (up to $82.4 \mathrm{~mW} \mathrm{~kg}^{-1}$ during moderate turbulence and $630 \mathrm{~mW} \mathrm{~kg}^{-1}$ during strong turbulence), although these results represent instantaneous snapshots compared to spatially and temporally integrated radar values, given by the size of the illuminated volume and the integration time.

$L_{B}$ was calculated to be about $1590 \mathrm{~m}$ and $400 \mathrm{~m}$ for strong and weak turbulence, respectively. Both values are large compared to the radar wavelength. It should be noted in this connection, that the observed wave mentioned may in turn induce superadiabatic lapse rates around the critical height causing a static instability which finally produces this sequence of turbulent bursts. In this case, however, $\omega_{B}^{2}$ becomes negative and the condition for deriving the energy dissipation rates is no longer fulfilled.

\section{Summary}

During the MAC/SINE-campaign in the summer of 1987 the SOUSY radar was operated to investigate cells of enhanced spectral width occurring in the upper 
sublayer of PMSE. Echoes received from different directions were used to derive the apparent velocity, the lifetime and the horizontal extent of these structures. The results can be summarized as follows:

1. The cloudlike cells of enhanced spectral width appeared mainly in the upper part of PMSE, i.e. above $86 \mathrm{~km}$

2. These cells were detected in about $10 \%$ of the total observation time only

3. Apart from some exceptions the spectral width was not correlated with the echo power

4. From the total spectral width the turbulent component $\sigma_{\text {turb }}$ was derived by substracting the beam and shear broadening which is related to the variance of the velocity

5. The lifetime (or the duration of occurrence) of these cells was of the order of 20 to $30 \mathrm{~min}$

6 . These cells moved with the same phase trace velocity as simultaneously observed gravity waves

7. Turbulent cells are argued to have been generated by a KHI mechanism

8. The horizontal extent of the turbulent cells was calculated to be less than $40 \mathrm{~km}$

9. The derived energy dissipation rates ranged from about 20 to $80 \mathrm{~mW} \mathrm{~kg}^{-1}$ during weak, and up to $500 \mathrm{~mW} \mathrm{~kg}^{-1}$ during strong turbulence

10. The outer scale of turbulence was large compared to the radar wavelength

Acknowledgements. The assistance of the staff of the Andoya Rocket Range in obtaining radar measurements is gratefully acknowledged. We thank Dr. P. Chilson for helpful comments and the technical staff of the SOUSY research group for operating the radar system. In addition we would like to thank the two referees for their very valuable comments. The antenna system of the mobile SOUSY VHF Radar was funded by the Deutsche Forschungsgemeinschaft.

Topical Editor F. Vial thanks T.A. Blix and another referee for their help in evaluating this paper.

\section{References}

Czechowsky, P., G. Schmidt, and R. Rüster, The mobile SOUSY Doppler radar: technical design and first results, Radio Sci., 19, 441-450, 1984.

Czechowsky, P., I. M. Reid, and R. Rüster, VHF radar measurements of the aspect sensitivity of the summer polar mesopause echoes over Andenes $\left(69^{\circ} \mathrm{N}, 16^{\circ} \mathrm{E}\right)$, Norway, Geophys. Res. Lett., 15, 1259-1262, 1988.

Czechowsky, P., I. M. Reid, R. Rüster and G. Schmidt, VHF Radar echoes observed in the summer and winter polar mesosphere over Andoya, Norway, J. Geophys. Res., 94, 5199-5217, 1989.

Cho J. Y. N., and M. C. Kelly, Polar mesosphere summer radar echoes: observations and current theories, Rev. Geophys., 31, 243-265, 1993.

Ecklund, W. L., and B. B. Balsley, Long-term observations of the Arctic mesosphere with the MST radar at Poker Flat, Alaska, J. Geophys. Res., 86, 7775-7780, 1981.
Gossard, E. E., Radar research on the atmospheric boundary layer, 477-527, in Radar in Meteorology, Ed. D. Atlas, American Meteorological Society, 1990.

Hocking, W. K., Mesospheric turbulence intensities measured with a HF radar at $35^{\circ} \mathrm{S}-\mathrm{II}$, J. Atmos. Terr. Phys., 45, 103-113, 1983.

Hoppe U.-P., T. A. Blix, E. V. Thrane, F.-J. Lübken, J. Y. N. Cho, and W.E. Swartz, Studies of polar mesosphere summer echoes by VHF radar and rocket probes, Adv. Space Res., 14, 139-148, 1994.

Inhester, B., J. C. Ulwick, J. Y. N. Cho, M. C. Kelly, and G. Schmidt, Consistency of rocket and radar electron density observations: implication about the anisotropy of mesospheric turbulence, J. Atmos. Terr. Phys., 52, 855-873, 1990.

Klostermeyer, J., A height- and time-dependent model of polar mesosphere summer echoes, J. Geophys. Res., 102, 6715-6727, 1997.

Klostermeyer, J., and R. Rüster, VHF radar observation of wave instability and turbulence in the mesosphere, Adv. Space Res., $\mathbf{4}$, 79-82, 1984.

Lübken, F.-J., On the extraction of turbulent parameters from atmospheric density fluctuations, J. Geophys. Res., 97, 20385-20395, 1992.

Lübken, F.-J., and U. von Zahn, Thermal strucutre of the mesopause region at polar latitudes, J. Geophys. Res., 96, 20841-20857, 1991.

Lübken, F.-J., W. Hillert, G. Lehmbacher, and U. von Zahn, Experiments revealing small impact of turbulence on the energy budget of the mesosphere and lower thermosphere, J. Geophys. Res., 98, 20369-20384, 1993.

Lübken, F.-J., J. Giebler, T. Blix, E. Thrane, W. Singer, and J. Bremer, In-situ measurements of the Schmidt number within a PMSE layer, Geophys. Res. Lett., 21, 1651-1654, 1994.

Röttger, J., and M. F. Larsen, UHF/VHF radar techniques for atmospheric research and wind profiler applications, 235-281, in Radar in Meteorology, Ed. D. Atlas, American Meteorological Society, 1990.

Rüster, R., Winds and waves in the middle atmosphere as observed by ground-based radars, Adv. Space Res., 4, 3-18, 1984.

Rüster, R., and J. Klostermeyer, Propagation of turbulence structures detected by VHF radar, J. Atmos. Terr. Phys., 49, 743-750, 1987.

Schmidt, G., R. Rüster, and P. Czechowsky, Complementary code and digital filtering for detection of weak VHF radar signals from the mesosphere, IEEE Trans. Geosci. Electron., GE-17, 154-161, 1979.

Taubenheim, J., Statistische Auswertung geophysikalischer und meteorologischer Daten, Akademische Verlagsgesellschaft, Leipzig, 1969.

Thomas, L., and I. Astin, The form of metre-scale turbulence at mesopause heights in the summer, J. Atmos. Terr. Phys., 56, 467-478, 1994.

Thomas, L., I. Astin, and I. T. Prichard, The characteristics of VHF echoes from the summer mesopause region at mid-latitudes, J. Atmos. Terr. Phys., 54, 969-977, 1992.

von Zahn, U., and W. Meyer, Mesopause temperatures in the polar summer, J. Geophys. Res., 94, 14647-14651, 1989.

Watkins, B. J., C. R. Philbrick, and B. B. Balsley, Turbulence energy dissipation rates and inner scale sizes from rocket and radar data, J. Geophys. Res., 93, 7009-7014, 1988.

Weinstock, J., Energy dissipation rates of turbulence in the stable free atmosphere, J. Atmos. Sci., 38, 880-883, 1981. 